\title{
A Righteous Undocumented Economy
}

\author{
Lee A. Swanson ${ }^{1}\left[\right.$ ] . Vincent Bruni-Bossio ${ }^{1}$
}

Received: 1 July 2017 / Accepted: 9 April 2018 / Published online: 25 April 2018

(c) The Author(s) 2018

\begin{abstract}
The academic literature commonly exposes large components of informal economies housed in developed countries as nefarious systems designed to help people evade taxes or carry on other illegal activities. However, our community-based participatory action study uncovered a significant element of a social and economic system that was largely undocumented, but was viewed as far more righteous than dishonorable and immoral. Our research involved approximately 375 participants from seven communities spread across a large and sparsely populated geographic region in the northern part of the Canadian province of Saskatchewan. The purpose for the research was to explore how entrepreneurship contributes to the good life, well-being, and prosperity by building social and economic capacity across a rural business ecosystem. We found that an important, yet undocumented part of the business ecosystem was grounded in history, culture, and tradition. When considered through a legitimacy theory lens, this perspective challenges the implication drawn from some of the academic literature that those who participate in informal business systems in developed countries usually do so for immoral reasons that might warrant a legal penalty. Further, we propose that researchers, policy makers, and community development professionals use the term undocumented economy rather than expressions like informal, hidden and underground economy to distinguish components of economic systems based on righteous motivations and activities from those founded on iniquitous practices and non-existent or unofficial record keeping. We begin this article with a definition for the undocumented economy in which we describe why we consider it to be righteous.
\end{abstract}

Keywords Community development · Hidden economy $\cdot$ Informal economy $\cdot$ Policy $\cdot$ Underground economy · Undocumented economy

\section{Introduction}

Feige (2016) listed the following terms that have been used in the literature to refer to economies that "all involve economic agents engaged in non-compliant behaviours that they seek to hide" (p. 5): "grey, black, subterranean, cash in hand, off the books, moonlight, undeclared, hidden, unofficial, concealed, parallel, invisible, occult, irregular, shadow, underground, non-observed, unreported, unrecorded, illegal, and informal" (p. 5). In this article, we use the term informal economy to refer to economic systems that are based in part

Lee A. Swanson

swanson@edwards.usask.ca

Vincent Bruni-Bossio

bruni-bossio@edwards.usask.ca

1 Edwards School of Business, University of Saskatchewan, PotashCorp Centre, 25 Campus Drive, Saskatoon, SK S7N 5A7, Canada on nefarious motives; however, we acknowledge that "informality is a multidimensional continuum" (De Castro et al. 2014, p. 75) that is not easily defined (Godfrey 2011). Some definitions for informal economy, like that used by Webb, Tihanyi, Ireland, and Sirmon (2009), parse out the illegal activities so the phrase means an economic system that is more legitimate than most meanings attributed to informal economy. In this article, we introduce and define the term undocumented economy to clearly distinguish the types of informal economies that are not based on nefarious motives.

In their review of the informal economy literature, Darbi et al. (2016) concluded that the research has, to date, focused on legal compliance with some advances made in differentiating criminal activity from other informal economy elements. They claimed that it was counterproductive to continue framing the informal economy as a wholly nefarious entity, and they highlighted the "need to enhance the state of knowledge about the 'ongoings' in the relationships between formal and informal sectors and 
businesses ... to shed more light on the embeddedness of informal firms in the value chains and networks of formal firms" (Darbi et al. 2016, p. 16). In contrast, the formal economy is characterized by "regulated economic units and protected workers" (Chen 2007, p. 6).

Our grounded theory, community-based participatory action study of a rural and remote area with a primarily young Indigenous population revealed an economy that blended formal activities with many that were not formally recorded in directories, reports, studies, statistical analyses, and other available publications. Most of those undocumented activities generated what might be considered employment income (occasional earnings) or gainful ways to make a living. When considered through a legitimacy theory (Suchman 1995) lens, those activities (other than some criminal elements, like the illicit drug trade) were legitimate in that they were accepted by the society in which they occurred because they aligned with its traditions, culture, values, and norms. But, there was a terminology and definitional void in the literature when it came to naming and describing the undocumented components of the economy we studied and, we believe, others like it, including some with non-Indigenous populations. To fill this definitional gap, we used the phrase undocumented economy, and defined it as follows:

An undocumented economy resides outside the formal economy, or blends with it in a complementary and mutually supportive way. It is righteous in that its participants do not actively seek to cause harm to individuals, organizations, or society through criminal action or by neglecting to adhere to laws and regulations deemed valid according to their lived context. It is explicitly or implicitly acknowledged as legitimate by those societal actors who give it continuing license to exist.

The term undocumented economy has not commonly been used among the myriad of terms for informal economies with nefarious elements. While the word undocumented has been paired with other words like immigrant and workers to indicate the illegal status of some people and activities, we believe that the phrase undocumented economy can be used to avoid the pejorative implications associated with other commonly used terms like black market and underground economy.

Our definition for the undocumented economy-the elements of which are explained in this article-should be of use to researchers, policy-makers, and economic development practitioners studying, developing policies for, and working with similar undocumented elements of regional economies. This work should also provide the opportunity to contrast our findings with those from urban settings in which undocumented economy elements may have weaker links to Indigenous cultural practices.

In this paper, we review the literature on informal economies while establishing that the concept of an undocumented economy as described above is absent. We then review the legitimacy theory literature, describe the research methods we applied, present our results, and discuss the implications while providing further support for the notion of - and need for-our definition of the undocumented economy.

\section{Literature Review}

Most of the literature on the informal economy has used terms like black market and hidden, underground, illegal, parallel, irregular, and shadow economy when describing those economic systems (Feige 2016; Fortin et al. 2010; Schneider et al. 2010, 2015). Some of those works, primarily from accounting, tax, and macro-economics journals, dwell on the disreputable elements of informal economies, mainly tax evasion, criminal activity, and labor standards violations. However, other literature focuses on informal economy components that are not necessarily nefarious because their participants do not deliberately intend to break the law (International Labour Organization 2013); the activities fit the definition of subsistence activity or household production (Petersen et al. 2010); the outcomes from the informal activity support formal elements of the economy (Darbi et al. 2016), and the activities are considered to be legitimate by large groups of people (Webb et al. 2014). But, there is no single term in current use that refers to relatively significant components of economies that are informal, but essentially righteous.

\section{Informal Economies}

Hart (1973) first used the term informal economy to describe the activities undertaken by those who have been unsuccessful at earning an adequate income in the formal system. However, there is no unanimity regarding the definition of the informal economy (Ghersi 1997; Godfrey 2011; Irarrazaval 1997). Welter et al. (2015) described informal economies as those in which business activity occurs that is at odds with the legal system, but is tolerated by society. The International Labour Organization "considers as informal those economic activities which use illegal means to achieve legal objectives" (Ghersi 1997, p. 224). Alternatively, it might be defined as economic activities that occur outside the framework of government regulation (Irarrazaval 1997). Defining what is meant by the informal economy is further complicated by the use of alternative or closely related terms. For example, the underground economy can be defined as "economic activity which would generally be taxable were 
it reported to the tax authorities" (Mirus et al. 1994, p. 236). Likewise, the term shadow economy has been associated with activities undertaken to avoid tax, but some researchers also use it to describe the economic actions people take to avoid the effects of excessive regulations, corruption, and bureaucracy (Bovi and Dell'Anno 2009).

\section{Elements of Informal Economies}

Schneider et al. (2015) referenced earlier works by Raczkowski to separate the overall economic system into the official economy based on legal compliance and the unofficial economy made up of two components; a grey economy in which the participants engaged in semi-legal activities, and the entirely illegal shadow economy. Included in this conceptualization of the grey economy are tax evasion, unregistered business operations, carrying on business without the required licenses and permits, inadequate declaration of income, insider trading, and similar illegal activities designed to help the perpetrators gain at the expense of society. It is apparent that this notion of the grey economy is founded on nefarious motivations.

Thomas (1992) separated informal economic activity into four components while describing it as that which is not recorded in the national accounts of most countries. One of his categories, the criminal sector, includes output from illegal activity like theft, the drug trade, prostitution, and extortion. He used the phrase the irregular sector to describe where activities like tax evasion, regulation avoidance, and social security fraud occur. This is also referred to as the black economy or underground economy. The output from this sector is legal, but the way in which it is produced or distributed is in some form illegal. The informal sector is generally associated with activity in developing countries where output is produced and distributed legally and exchanged through market transactions, but is not recorded in national accounts because the systems to collect the data have not yet been adequately developed. The household sector includes production that is not traded, but is instead consumed by those who produced it. The activities included in this sector are legal, but do not give rise to market activity. This means that no prices are established to enable values to be calculated and included in national accounts.

Consistent with terminology used in economics and sociology research, Webb et al. (2009) defined "the informal economy as the set of illegal yet legitimate (to some large groups) activities through which actors recognize and exploit opportunities" (p. 492). They then used the term renegade economy to describe the remaining set of illegal activities, those that were not considered to be legitimate. By expanding the polar concept of formal and informal economies into formal, informal, and renegade, Webb et al. (2009) equated informal to our concept of an undocumented economy.

\section{When Informality Does Not Mean Bad Intentions}

Petersen et al. (2010) noted that a distinction should be made between criminal activities that do harm to society and shadow economy activities that, despite their association with tax evasion and transfer fraud (when individuals benefiting from social welfare transfers are also illicitly collecting income from work they are doing), can increase overall income and wealth. They also acknowledged that modern economies include some subsistence activities that are part of the informal economy, but are not nefarious.

The International Labour Organization (2013) acknowledged two interrelated perspectives of the informal sector. One defines the sector as comprising enterprises that do not conform to the legal and administrative framework. The second perspective separates informality from business registration and instead defines the informal sector according to how production occurs to allow for the fact that different jurisdictions have different registration requirements. Under both perspectives "the vast majority of informal sector activities provide goods and services whose production and distribution are perfectly legal.... [and] are not necessarily performed with the deliberate intention of evading the payment of taxes or social security contributions or of infringing labour legislation or other regulations" (International Labour Organization 2013, p. 47).

Petersen et al. (2010) separated the overall economy into the market, shadow, and household sectors. The market sector represents the official economy and the shadow sector is where transactions are hidden and "are at least partly connected with tax evasion or transfer fraud" (p. 422). They considered subsistence economy activities, like when people grow some of their own food to consume themselves or make some goods rather than purchasing them, as analogous to the household sector as those activities are called household production in some national accounting systems. While household production is different from shadow economy production, it is equally as unobservable. As household production is mostly non-monetary in nature, it is not subject to market factors that generate relative prices, so, even if it was observable, it would be difficult to value. It is also not subject to taxation if the output is consumed by those who produced it. "Household production was almost totally neglected in theoretical as well as empirical economics for decades, until the discussions on the emerging shadow economy started in the 1970s" (Petersen et al. 2010, p. 425). Since then, insufficient assessments of household income have resulted in inaccurate estimates of its probable considerable impact on living conditions in both developing and developed countries.

Our undocumented economy concept includes the activities that Petersen et al. (2010) described as part of the household sector, but also some they included under the shadow 
sector. As described later, some of the economic activities that Petersen et al. (2010) would consider as shadow sector happenings because they did not generate tax revenue would, in the region we studied, be widely considered to be legitimate, and thus part of what we call the undocumented economy.

\section{How Informal Economies Arise}

Most descriptions of how and why informal economies arise indicate income and consumption tax avoidance as a prime motivator. For example, Petersen et al. (2010) explained that subsistence economies, in which households sought only to satisfy their own needs, evolved into barter economies when specialization enabled the production of surplus goods and services to exchange with others. As barter economies became monetized, they evolved into modern economies that relied on taxation to provide public goods and services. As tax burdens increased, incentives arose that caused some individuals to shift their production and consumption to informal components of the overall economy to avoid paying taxes. As production from those informal components is not included in national accounts, "the tax and social security contribution bases in the market sector are reduced-tax evasion is taking place" (p. 423).

\section{How Informal Economies Dissolve and Persist}

There is a "widely held belief among mainstream economists that informal work dissipates or disappears as nations or areas within them develop economically" (Marcelli et al. 2010 , p. 1). This view is based on an underlying assumption that people undertake informal work because they lack opportunities to participate in the formal economy. Firms become more motivated to enter the formal economy when they feel they can benefit from its functional legal system or when they grow or mature enough to be able to benefit from government programs or exporting or other programs and activities that require formal records and visibility (Besley and Persson 2014).

De Castro et al. (2014) claimed that firms in formal and informal economies develop an integrated exchange system that provides legitimacy to firms operating informally, which provides opportunities for them to persist. Theorists like Acemoglu and Robinson (2012) support this notion by demonstrating that the institutions that monitor transactions and other activities dictate the systems that evolve. Those institutions might actively regulate economic activities, leading to more formality in an economy, or they might allow informal economic elements to persist by neglecting to actively enforce their regulations.

\section{Perspectives of the Informal Economy Influence Policy}

Estimates of the sizes of informal economies are difficult to calculate because of the absence of available records and disagreement on the best methods to use. Researchers focusing on the informal economy as a means to avoid taxes typically estimate its size based on national accounting data while those viewing it as a phenomenon influenced by social, geographic, and other factors usually collect their data from those involved in the informal economy. "What we learn from these very different types of studies shapes the policies that are advocated for or against the informal economy" (Joassart 2010, p. 34).

\section{Legitimacy Theory}

Suchman (1995) defined legitimacy as "a generalized perception or assumption that the actions of an entity are desirable, proper, or appropriate within some socially constructed system of norms, values, beliefs, and definitions" (p. 574). Legitimacy theory says that society will judge an organization to be legitimate or not within the social environment in which it resides (Bhattacharyya 2014) based upon whether its value system is congruent with that of that society (Chen and Roberts 2010). If society considers an organization to be behaving in illegitimate ways, it might revoke the organization's ability to continue to operate (Eweje 2006). "Legitimacy is possessed objectively, yet created subjectively" (Suchman 1995, p. 574), meaning that it is not government agencies and other official entities that bestow legitimacy; instead, it is conferred by others within the societal sphere of the organization (Chen and Roberts 2010). "An organization does not have to gain approval from all of society. It can achieve its legitimacy if it can gain support from enough parties to ensure its survival" (Johnson and Holub 2003, p. 270).

According to Suchman (1995), there are three types of legitimacy; pragmatic, moral, and cognitive. Pragmatic legitimacy is conferred on an organization by stakeholders who expect to benefit from the actions of that organization though direct exchanges or in more general ways, like through "political, economic, or social interdependencies" (p. 578). Moral legitimacy is based on beliefs that an organization is doing the right thing. Cognitive legitimacy is bestowed by those who believe that what an organization does should make sense in a way that gives it legitimacy. This kind of legitimacy might be based on evaluation or on a "mere acceptance of the organization as necessary or inevitable based on some taken-for-granted cultural account" (p. 582).

We applied the methods described next to detect, using grounded theory and community-based participatory action research, what appeared to be a relatively sizeable 
undocumented component of a regional economic system defined by its remoteness and its mainly Indigenous and youthful population. We then applied a multimethod approach to gather local perspectives on the regional economy, including its undocumented component.

\section{National and International Context}

\section{Governments and Northern Indigenous Communities}

Canada's northern communities are in its three northern territories and in the seven sub-Arctic provincial north areas. In the provincial north regions alone, seven distinct political systems at the federal, provincial, and local levels are at play. The "Provincial North, as a unit of political analysis, is defined more by fragmentation and difference than by political or administrative structures" (Coates et al. 2014, p. 6). In jurisdictions like this, political power can rest with a plurality of groups or a broad coalition of institutions, which might neglect to enforce regulations that would force informal economies to become more formalized (Acemoglu and Robinson 2012).

\section{Misconceptions About Informality in Indigenous Communities Negatively Impacts Policy Development}

Natcher (2009) described the "complex social, economic, and political interplay that takes place between subsistence and wage economies, sharing and reciprocity, and regulatory regimes" (p. 84) that characterize the communities across the Canadian north; communities that are predominantly Indigenous and maintain the hunting, gathering, and fishing lifestyles that have long been part of their cultural identity. He also highlighted how the literature has framed these partially subsistence-based economies as informal, which has stigmatizing them as non-progressive and backward, leading to "ill-conceived policies derived from outdated theories of modernization that assume subsistence economies will be subsumed as development proceeds on national and global scales" (p. 85).

Ommer and Turner (2004) added that a challenge to mobilizing the political will to develop and implement programs to help rural resource-based communities achieve the levels of sustainability enjoyed by urban regions stems from a perception held by some decision-makers that rural communities are an economic drag because they are outdated and inefficient. The attribute this to their "notvery-visible 'informal' economic structures, which are not only economic in nature but also social (including ethical 'rights' or obligations) and cultural" (p. 129).
Informality in Indigenous Communities as Lens Into Non-Indigenous and Formal Contexts

The informal economy is linked to the formal economy, and studies at the boundaries of the two can shed light on foundational management concepts (McGahan 2012). Studying the informal sector Indigenous contexts-including in places like Africa — can offer insights into Indigenous management practices and into the "implicit assumptions of 'Western' views of management ... [and] the transferability of practices between Indigenous informal business behaviours and practices, and formal more 'Western' management practices" (Darbi et al. 2016, p. 14).

\section{Methods}

Our 5-year research project, launched in 2013, sought to ensure that the study was conducted with and for the communities in the region under study instead of $o$ them. It applied a community-based participatory action research (CBPAR) approach as that method "has evolved as an effective new research paradigm that attempts to make research a more inclusive and democratic process by fostering the development of partnerships between communities and academics to address community-relevant research priorities" (Flicker et al. 2007, p. 478). Accordingly, the project began with an invitation to community members from across the region to participate as research partners.

Guided by research objectives, including those developed with research partners from the communities, the research team used grounded theory to inductively build theory, rather than develop and then test hypotheses. Consistent with grounded theory principles, the team developed the research methods with the expectation that they would need to adapt to evolving and changing conditions while also following the data collection and analysis procedures prescribed by the approach (Corbin and Strauss 1990; Strauss and Corbin 1990).

\section{Methods for Conducting Research with Indigenous Communities}

In Canada, Indigenous people-First Nations, Inuit and Métis-are those whose descendants lived in what is now Canada before Europeans settled there. According to the 2011 national census, $86.9 \%$ of the 36,785 residents of the region under study were Indigenous Canadians, particularly First Nations and Métis. Of that Indigenous population, $35.5 \%$ were under the age of 15 (Statistics Canada 2011).

The region under study was the northern part of the province of Saskatchewan, a vast region measuring $269,996 \mathrm{~km}^{2}$. The population lived in small, rural, remote, and often 
economically and socially disadvantaged communities compared to the people in the more southerly parts of Canada (Sisco and Stonebridge 2010). This is despite the fact that northern Saskatchewan is rich in natural resources. The region is the second largest uranium producer in the world. Over one million ounces of gold have been extracted from there over the past 20 years, and forestry, commercial fishing, and tourism industries have operated there for decades. Additionally, "rare earth elements, base metals, oil sands and graphite deposits all hold potential, as well, for future mines in the region" (Northern Development Ministers Forum 2016, Mining and Exploration, para. 2).

Canada's Tri-Council Policy Statement on Ethical Conduct for Research Involving Humans recognized that nonIndigenous people have conducted much of the research with Indigenous communities, and the approaches they applied often did not reflect Indigenous world views and did not necessarily benefit the Indigenous peoples or their communities (Government of Canada 2014). The comprehensive framework laid out in the policy statement provides guidance for researchers working with the country's Indigenous peoples in recognition of their "unique histories, cultures and traditions" (Government of Canada 2014, p. 105). The Tri-Council policy guidelines "may also be an important source of guidance for research involving other distinct communities" (Government of Canada 2014, p. 110) and it may provide one of the most relevant and comprehensive set of guidelines for conducting research in regions made up primarily of rural and remote communities.

The research team's approved research ethics application drew heavily from the Tri-Council Policy Statement chapter on Research involving the First Nations, Inuit and Métis Peoples of Canada (Government of Canada 2014) to ensure that its CBPAR approach would respect the knowledge and experience that participants would contribute to the research process, and provide meaningful outcomes that they could use (Brydon-Miller et al. 2003; Schmidt 2009). Accordingly, from its start, the project involved members of the communities of the region under study as research partners from the study's conceptualization to the presentation of its outcomes.

\section{Multimethod Approach}

The research team applied a qualitative multimethod approach to the study. Youth data collection workshops were held during the mornings or afternoons at the high schools in seven communities across northern Saskatchewan with grade 10,11, and 12 students. A total of approximately $200^{1}$

\footnotetext{
1 These figures are approximate because some of the Photovoice participants also participated in the data collection workshops and some community members participated in only some parts of the data collection workshops.
}

youth participated in those workshops, comprising focus group discussions and a variety of visual methods, including drawing on a map to indicate perceptions of community, using flash card prompts to generate discussion about economic activity within and between communities, and participating in an OurVoice peer-to-peer video interview (Swanson et al. 2016) exercise to record their perspectives on the futures of their communities.

The team also conducted community workshops in six of the seven locations visited. Those workshops involved approximately 150 adult members of the communities and included focus group discussions and map-marking and flash card exercises. An additional 25 community members, including some who also participated in the workshops, volunteered to participate in Photovoice, a method where the participant took or selected photographs in response to an interview question and used those images during an interview (Wang and Burris 1997). Research team members gave the Photovoice participants cameras and a question about the nature of entrepreneurship in their community during the visit to conduct the community workshop, and returned about two weeks later to conduct the interview.

\section{Data Analysis}

Transcripts were prepared from the field notes and recordings generated from the youth workshops, community workshops, and Photovoice sessions. An open coding phase followed where two trained Research Assistants independently coded the data from the transcripts using NVivo qualitative analysis software. After another round of coding to combine the independently generated codes and reconcile any conflicts between them, themes emerged from the data from each of the seven communities and from the combined northern Saskatchewan region. Research Assistants then conducted a deep coding phase on the combined dataset to extract any additional emergent themes. The third and final round of coding, called thematic coding, was applied to detect linkages and relationships between the emergent themes.

The research team also analyzed a wide range of secondary resources, like business directories, corporate reports, academic studies, statistical data, resource extraction information, and government documents. From this information, the team was able to construct a map of the businesses and other organizations making up the documented components of northern Saskatchewan's business ecosystem. When research participants identified goods and services that were exchanged in their communities that did not appear to have been provided by documented businesses, those activities were considered to be part of the undocumented economy.

The following section describes the results from our research. Although about 200 of the approximately 375 
participants made their contributions through the youth data collection workshops in the seven participating communities, we did not find any notable distinctions between their contributions and those from the participants in the community workshops. Hence, the following results are based on aggregate data.

\section{Results}

Key emergent themes from the research project included the importance of community, the persistent and important connections between communities across the vast rural and remote region, the blending of the documented and undocumented components of the economy, the blending of the modern and traditional economies, and the challenges associated with living in a rural and remote region. Influencing all of these themes was the significant and formative role played by their common history, culture, and traditions.

The following illustrates how elements of the emergent themes confirm the existence of an undocumented component to the regional economy we studied, why it exists, and how it works. We also explain how the research outcomes indicate regional legitimacy for the undocumented economy and how and why it persists as a perceived legitimate economic system.

\section{The Blended Documented-Undocumented Economy}

The region under study housed an entrenched formal economy comprised local businesses, large mining and retail enterprises based elsewhere, and community-owned ventures-like Indigenous development corporations that owned and operated businesses across the region or invested in a portfolio of businesses operating in other places. The area also had a network of education, financial, and other organizations that sought to support enterprise development in the region.

Research participants were aware of how organizations that were part of the formal economy contributed to the well-being of people living in their communities, and they appreciated the need for, and the influence of the formal monetary-based system. However, they also openly and readily described what they viewed as the equally important network of undocumented organizations and activities that blended with the formal components of the regional economy. One participant said, "people need money to survive because we live in a capitalist system, but ... people still do traditional kinds of things."

One participant's comments reflected the general feeling that northern Saskatchewan had many "home businesses that don't [purchase business licenses] that are providing essential services to the community; but we don't even know they are [not formally registered businesses] because they are a part of the local economy." Most participants shared knowledge and experiences that supported the benefits derived from the undocumented activities across the region. One indicated that "they borrow from each other and they will trade different things off to each other as a barter system ... that might be beneficial to individuals that don't have or don't wish to spend a lot."

According to research participants, the undocumented economy across northern Saskatchewan was based on giving, sharing, and trading activity, much of it tied to traditional practices and cultural norms. For many, perhaps a majority, of the people in the region, the traditional and culturally steeped practices of hunting, fishing, trapping, and gathering were simply a way of life. In some cases, these activities were part of the formal economy and people who made their living by trapping and paid taxes on that income. However, unlike in most other economic regions, many people in northern Saskatchewan supplied their own food by hunting caribou or moose, catching their own fish, and picking berries, mushrooms, and other foods-activities that were not formally documented through the taxation or other systems. Hunting and trapping provided people with animal hides needed to make clothing and crafts to use themselves, or to sell. Some people gathered plants necessary to make traditional medicines as an alternative to purchasing modern pharmaceuticals.

\section{Giving}

It was common for people to acquire more of something than they needed, like firewood for the winter, so that they could give away the excess to help the Elders and others in their communities. Among the items that participants said that people regularly gave to others in their communities were as follows: food (bannock, fish, moose meat, and other traditional foods), moccasins, moose hide, traditional medicines, sporting equipment, household items, and beadwork and other arts and crafts. People also gave each other services, like babysitting, and other things of value, like advice and time. In one community, a particular person prepared all of the gravesites before funerals without asking for or receiving anything in return.

\section{Sharing}

Community members shared items like the following: moccasins, fish nets, tools, tobacco, and traditional foods like berries and caribou meat. Services like babysitting and haircutting were also shared between people as were traditionbased things like hunting grounds, trap lines, and knowledge shared by community elders. Some participants said 
that community members shared stories, traditions, music, friendship, and time.

Included in the notion of sharing was when family members provided sustenance for each other. One Photovoice participant indicated that when they hunted for food, they always shared the product with their children and their parents. They only hunted for the quantity of food needed by their family, and did not take extra.

Community gardens had historically played a role in providing food to local people, and were being reintroduced to some communities. In one community, a participant noted that some families grew more food than they needed so that they could share it with others.

\section{Trading}

Two of the research partner communities were established as fur trading posts in the 1770s when newcomers from Europe first arrived in the region; however, the Indigenous peoples from the region traded among themselves long before then.

Europeans wishing to trade with interior Indian peoples, found a pre-existing system of alliances and exchange networks and had no choice but to try to fit into it. To do so, they had to recognize and respect trade protocols and adopt these symbolic practices and the obligations that went along with them as their own.

(Waiser 2016, p. 97)

One research participant said "people have always traded here."

Among the items that participants said were regularly traded between people at the time of the study were home appliances and vehicles like cars, boats, ATVs, motorbikes, and snow mobiles. Some of the traded items were those with strong cultural connotations, like animal traps, medicines, animal furs, and traditional foods like moose meat and fish. Traditional foods acquired through hunting, fishing, and gathering were often traded to others for food purchased in stores. Some respondents indicated that people would trade items for knowledge. Respondents referred to the barter system used in their communities, and indicated that often goods were traded for services.

While examples of giving, sharing, and trading were most often framed as normal and beneficial exchanges, several participants expressed concern over some that were destructive to their communities, namely those involving illegal drugs and liquor.

\section{Role of Technology}

Participants from across northern Saskatchewan referred to how websites and social media had emerged as a major way for them to facilitate and cultivate the giving, sharing, and trading that occurred. One participant called it the "hidden community infrastructures," and a claim from a focus group discussion was that this use of technology had "become the primary method of buying and selling things here in the community. It's much more prevalent than down south."

Communities across the region had local Facebook pages used as online buy-sell-trade sites that they called "E-Buy" and "Free-Bay." In some communities with Indigenous populations descending from the Cree people who had lived across the region for thousands of years, some online buysell-trade sites were referred to locally as "Cree-Bay" or "Cree-Way."

Participants claimed that most of their communities had vibrant undocumented trading systems enabled by technology. An online search by research team members confirmed that most communities had these buy-sell-trade sites, many of which restricted access to local users. Both used and new items were available for sale or trade on the sites, and they were also used to ask for or offer services like vehicle rides to the city for doctors' appointments and other purposes.

Another claim that emerged from the focus group sessions was that some people used the Internet on their own to sell their items online and to get ideas to help them make and sell handicrafts and other items.

\section{Why Residents Felt the Undocumented Economy was Legitimate}

The undocumented component of the regional economic system we studied was based in part on cash transactions that one participant said was "legal in every [other] respect, but it's not reported so they aren't paying taxes.” But, far from being considered as something bad, participants said that undocumented businesses "really build capacity and develop community at the local level" and it "could help build work and sustainability opportunities." This appeared to be the common sentiment among the research participants who almost unanimously accepted that the undocumented part of their economy-minus the illicit drug trade and other illegal elements undermining positive community development - was a normal and accepted part of life in their region. They openly and readily discussed all elements of their regional economy without distinguishing between the documented and undocumented elements.

Consistent with Suchman's (1995) definition of legitimacy, the people of the region viewed the undocumented giving, sharing, and trading elements of their economy as desirable and appropriate based upon their traditions, values, and norms. In relationship to the three types of legitimacy, the research participants considered the undocumented components of their economy to be legitimate in a pragmatic sense because they were consistent with their ways 
of living. The undocumented components were also viewed as morally and cognitively legitimate because, in part, they helped maintain and preserve centuries old traditional ways of living.

Research participants generally viewed their blended economy as different from the other regional economies in the province, and attributed its development and existence to the history and culture of northern Saskatchewan. They felt that the people who made decisions for their region but did not live there did not understand their blended documented-undocumented economy that was based in part on hunting, fishing, and gathering along with their giving, sharing, and trading traditions. The following grievances expressed by the participants seemed to further justify their belief in the legitimacy of the undocumented elements of their economy.

\section{Misunderstood by Decision-Makers Who Did Not Live There}

Some respondents indicated that the decision-makers who impacted their region, but did not live there, did not understand that-as one respondent framed it- the "spiritual, cultural, and economic" components were highly integrated. They felt that the decision-makers viewed the world through an urban lens that was inappropriate for understanding their region. "Maybe that is why governments and agencies can't attach support to something like this; because they can't understand the connection of all the pieces." One respondent gave the example of decision-makers who had "absolutely no comprehension that snowmobiles are working vehicles and are not just for recreation."

\section{Ineffective Government Support}

Residents of the region felt that many government programs failed in their efforts to reduce the substantial gap between their area and the more heavily populated regions in the effectiveness of the services provided. In the words of one respondent, governments applied a "shotgun method" where they introduced one short-term program after another to improve health services, housing quality, drinking water safety, and recreation provision without lasting effect. They also felt that there was a shortage of healthcare workers and teachers in the region.

\section{Policies and Programs Based on Incomplete or Inaccurate Information}

Consistent with Joassart's (2010) claim that the theoretical and methodological approaches to measuring the size of the informal economy shape policies that either seek to support it or suppress the activities in that economy, the research participants felt that government decisions were influenced by how decision-makers sought to understanding their region. One participant said, "[in] the last census they counted about 2300 people, so the town lodged an official complaint to Stats Canada saying it [was] closer to 3000 , we are [a] small town, we can count houses." This participant indicated that the town submitted an appeal supported by its own data, which lead to Statistics Canada increasing the population count to about 2700 people. However, the participant felt that the result disadvantaged his community. "They don't change all of the rest of the data that falls under it, so it's unfortunate if you're a town or village trying to get funding."

\section{Laws and Regulations Designed for Other Contexts}

Some participants highlighted the challenges that can arise when people living traditional lifestyles in the blended northern economy are subject to the laws developed for other contexts. The following examples provided by a Photovoice participant illustrate this dilemma.

People who have hunted for centuries with their families ... have guns, and then all of a sudden gun legislation comes in and everybody who's got a gun ... if they don't have it registered, they're criminals right? It criminalizes people ... that's not fair. You've got elders $\ldots$ and they're not literate and ... they struggle with those things ... all of a sudden ... if they traded fish for stuff $\ldots$ and they do that now, then they're poaching.

\section{Uncertainty over the Tax Rules}

The Photovoice participant went on to say that many of their "traditional things have been really suppressed because of government, legislation, and things like that." The participant felt, for example, that people were unclear about whether they are supposed to pay tax on the income they made from selling the types of traditional products their ancestors had made for subsistence, but that were now considered to be crafts that others from outside their community wished to purchase; activities did not evolve into large scale ventures.

\section{The Persistence of the Perceived Legitimate Blended Economy}

Research participants stressed the strong sense of community that extended across their region. Some, like the participant who said the following, drew comparisons between their region and those to the south: "coming from the south, there is almost an assumption that you are looking out for yourself. Living here it is much more of an assumption of community. You will help each other out. It's hard to quantify but it's just 
the little things that just don't happen in cities and especially down south." Others elaborated on this by saying: "it's much more inclusive up here," "you get to know people in ways you wouldn't in a large community," "the advantage of being in a small community is that you can relate to more people, know more people," and "I don't think it makes sense to live in larger communities." During one focus group discussion, the sentiment was that "when someone asks you for help, you try and give help because you never know when you're going to need help somewhere down the road."

Some youth in the participating communities expressed their desire to gain a postsecondary education in the south and then move back to their home communities to provide medical and other services needed there. Other community members lamented the fact that some elders had to move away from their home communities for health reasons, but ended up living in unfamiliar places away from family and friends.

The above comments reflected the fact that the communities in the region under study were more remote and isolated than communities to the south. They were also more sparsely populated, and the residents traditionally had to rely more heavily on one another to meet their basic needs than was generally the case with southern communities. Participants did not indicate that they foresaw any major change in how their economy was structured. These responses and factors appeared to reinforce both the strength of the current blended documented-undocumented regional economy and its perceived legitimacy.

Some of the respondents from the seven communities across Saskatchewan's north that participated in the study indicated that there were strong connections between the communities. One respondent said, "I'm always talking to people in surrounding communities. We're all really interconnected with people, even those in the far north." Others verified this by saying "there is a lot of mobility, even with how remote these communities are," "you always reach out to people you know to support you, networks and word of mouth," and "you drop-in, people pass through communities."

These strong connections between communities was significant because it reflects the cultures, family ties, and community challenges shared across the region, despite the vast distances between centers (some communities can only be accessed by air) and even the cultural distinctions between the Indigenous communities (some were mainly Cree and others comprised the Dene people). This implied that they saw their current way of doing things as legitimate and persistent.

The following section discusses how the definition for the undocumented economy emerged from our research along with some of the implications from the study.

\section{Discussion}

Legitimacy theory suggests that those residing within a particular social context will make their own determination regarding the legitimacy of a societal reality, like a particular economic structure (Bhattacharyya 2014; Chen and Roberts 2010; Suchman 1995). To date, some researchers have framed informal economies as illegitimate entities because they have been presumed to exist mainly to evade taxes or avoid compliance with employment and other laws (Bovi and Dell'Anno 2009; Feige 2016; Ghersi 1997; Mirus et al. 1994). Other scholars have excluded illegal activities from their conceptualizations of the informal economy (Webb et al. 2009), focused on the subsistence and household production components (Petersen et al. 2010), and studied how informal elements support the formal economy (Darbi et al. 2016). Our study of a regional economy that had an informal element that was not based on nefarious motivations and was considered legitimate by the residents of that region highlighted the need for a distinct descriptor.

To fill this gap, we introduced the phrase undocumented economy, and defined it in the introduction to this paper. The following paragraphs explain the elements of the definition as supported by our research outcomes. After that, we explain why undocumented economies might be more persistent than informal economies and the research and policy implications from our work.

\section{An Undocumented Economy Might Blend with a Formal Economy in Complementary and Mutually Supportive Ways}

Darbi et al. (2016) claimed that researchers need to acknowledge that the formal sector of the economy sometimes blends in productive and desirable ways with undocumented elements of the economy, particularly as they might work together to support value chains and network associations.

The undocumented economy we examined blended seamlessly with the formal economy. This was probably due in part to the fact that many of the undocumented elements existed from before the formal economy was introduced to the region. The regional economy is still heavily influenced by the traditional lifestyle activities, including hunting, fishing, gathering, and trapping, and to the cultural norms of giving, sharing, and trading. Even the youth in the communities said that they valued the traditional lifestyles and wanted to adhere to the cultural norms. It seems clear that the undocumented economy of the region blends with the formal economy in a complementary and mutually supportive way. 


\section{The Undocumented Economy as a Righteous and Legitimate Economy}

We used the phrase undocumented economy for two reasons. First, the community research partner who first advised the team to assess the undocumented components of the regional economy used that descriptor. When he and others familiar with the region under study referred to the undocumented economy, they were almost exclusively talking about historical and culturally grounded elements of the economy, and not nefarious components. Second, we found that researchers rarely used that phrase in their academic articles, but the other words and phrases used did not fit the circumstances of the region we studied.

Other than for some illegal activity, primarily the drug trade, the participants in the region's undocumented economy were clearly striving to live their lives without harming others. It was not clear whether, for example, individuals who do not report income from activities like gathering and selling berries viewed their actions as denying the government deserved tax dollars. However, it was clear that residents of the region felt that they received inadequate government support relative to their southern neighbors, often due to the decision-makers living elsewhere and not understanding life in the north, relying on inadequate or incomplete information, and applying laws and regulations that did not work in the northern context. Perhaps this perspective provided justification for many for not reporting their income from the undocumented economy.

Finally, the people of the region appeared to bestow legitimacy on their undocumented economy, and considered it to be a normal and essential part of their lives. None of our participants indicated that they viewed elements of their undocumented economy (which, according to our definition, excludes criminal behavior) as illegitimate enough to take measures to prevent it. On the contrary, the respondents almost unanimously supported their undocumented economy as it helped promote and preserve elements of their traditional lifestyle as it was consistent with their culture.

According to Khlif et al. (2016) some populations might factor in their interpretations of signals from governments when they make legitimacy determinations. As our research respondents did not reference any examples of governments penalizing or prosecuting small, undocumented businesses in the region under study for not complying with taxation and business documentation requirements, legitimacy theory implies that this government action (or inaction) might have played a role in the societal acceptance of the undocumented economy in the region as legitimate.

\section{Why Undocumented Economies Might Persist}

The unique and functional ways in which the residents of northern Saskatchewan have applied technology to support their undocumented economy may be helping them to preserve and advance it. In doing so, they seem to have found a means to protect their historical and cultural heritage. However, the use of technology across the region was weighted toward supporting buying, selling, giving, sharing, and trading within and across the communities located there. Website searches and analysis by research team members found a modest number of sites available to support sales of products from northern crafts and business people to those located elsewhere. This might be partly due to the poor Internet services available in the large and sparsely populated region.

Some perspectives on the forces that cause informal economies to disappear or to be absorbed into the formal economy may not apply in the case of the undocumented economy in the region we studied. Among these is the economic-based view that informal work will disappear as economies become more vibrant and people have access to more formal employment opportunities (Marcelli et al. 2010). Although increases to economic prosperity through the formal economy in the region we examined was somewhat dependent upon mining in the region carried out by large companies located in the south and, in some communities, community development corporations, the undocumented economy appeared to be somewhat resilient. This might have been, in part, due to some people opting to assume traditional lifestyles and the giving, sharing, trading culture. It might also have been partly due to the limited opportunities available to the people of the region when mining activity expanded. This might be particularly true of late when increases in automation have created employment opportunities for which local people are not qualified.

Another economic-based perspective is that informal economies will dissipate when those engaged in informal activities become motivated to enter the formal economy when they feel it provides them with legal benefits, government programs, and business opportunities they cannot access outside of the formal economy (Besley and Persson 2014). It appears that the highly developed Canadian economy has not yet provided the promise of enough benefit to attract all of the participants of the undocumented economy to the formal economy side.

Consistent with the findings by De Castro et al. (2014), another force enabling the persistence of the undocumented economy in the region might be its high level of integration with the formal economy. The mutual benefits afforded both elements of this blended undocumented-formal economy by its integration might be one reason why the undocumented economy appears to continue to thrive in the region. Another reason, based on insights by Acemoglu and Robinson (2012), might be that the institutions that regulate this economic area simply neglect to enforce the regulations, thereby allowing the undocumented economy to persist. 


\section{Research Implications}

Darbi et al. (2016) indicated that the focus has been on studying informal economies as vehicles for nefarious tax avoidance and hiding dubious labor practices. That good work should be complemented by studies of undocumented economies, like the one we observed, in which-as our definitions says-"participants do not actively seek to cause harm to individuals, organizations, or society through criminal action or by neglecting to adhere to laws and regulations deemed valid according to their lived context. It is explicitly or implicitly acknowledged as legitimate by those societal actors who give it continuing license to exist."

Another research implication with a significant ethical element is derived from Joassart's (2010) observation that government policies are shaped in part by the results from research. When most of the research output is about informal economies that provide a system for tax avoidance, and there have been few studies of righteous undocumented economies, the policies developed might be equally skewed toward detection, prevention, and punishment rather than toward enabling blended formal-undocumented economies to thrive.

\section{Policy Implications}

Consistent with Natcher (2009) and Ommer and Turner (2004), this study of a rural and remote social and economic system in northern Canada found that policy makers need to be aware that their data might be incomplete or inaccurate and the resulting laws and regulations might not be best applied in other contexts. They should also embrace the notion of a righteous undocumented economy that might complement and support the formal economy, be founded on virtuous motivations, serve a region for which existing laws and regulations are not designed, and that is considered legitimate by the societal actors who interact with and within it and seek to ensure its continuance.

\section{Conclusion}

The research project uncovered important insights into a rural, undocumented economy based on history, traditions, and culture. The evolution of that economy as it blended with the modern monetary-based systems linking it with the rest of the world resulted in a sizable proportion that remained undocumented. However, the undocumented element was not the same as traditional notions of underground or informal economies. Instead, the undocumented activity forming part of the northern Saskatchewan business ecosystem was a means to preserve and maintain important traditions and culture. These new insights, along with our definition of the undocumented economy, should provide researchers, policy makers, and community development professionals with a fresh and needed perspective that is unencumbered by the negative connotations of the terms used to date. That can lead to better research, policy, and development outcomes.

Funding This research was supported by the Social Sciences and Humanities Research Council of Canada (Grant Number 435-2013-1288).

\section{Compliance with Ethical Standards}

Conflict of interest Lee A. Swanson and Vince Bruni-Bossio declares that they have no conflict of interest.

Ethical Approval All procedures performed in studies involving human participants were in accordance with the ethical standards of the institutional and/or national research committee and with the 1964 Helsinki declaration and its later amendments or comparable ethical standards.

Informed Consent Informed consent was obtained from all individual participants included in the study.

Open Access This article is distributed under the terms of the Creative Commons Attribution 4.0 International License (http://creativeco mmons.org/licenses/by/4.0/), which permits unrestricted use, distribution, and reproduction in any medium, provided you give appropriate credit to the original author(s) and the source, provide a link to the Creative Commons license, and indicate if changes were made.

\section{References}

Acemoglu, D., \& Robinson, J. A. (2012). Why nations fail: The origins of power, prosperity, and poverty. New York: Crown Publishers.

Besley, T., \& Persson, T. (2014). Why do developing countries tax so little? Journal of Economic Perspectives, 28(4), 99-120.

Bhattacharyya, A. (2014). Managerial attitude and support for social responsibility through the lens of legitimacy theory-A cross country comparison. Social Responsibility Journal, 10(4), $716-736$.

Bovi, M., \& Dell'Anno, R. (2009). The changing nature of the OECD shadow economy. Journal of Evolutionary Economics, 20(1), $19-48$.

Brydon-Miller, M., Greenwood, D., \& Maguire, P. (2003). Why action research? Action Research, 1(1), 9-28. https://doi. org/10.1177/14767503030011002.

Chen, J. C., \& Roberts, R. W. (2010). Toward a more coherent understanding of the organization-society relationship: A theoretical consideration for social and environmental accounting research. Journal of Business Ethics, 97(4), 651-665. https:// doi.org/10.1007/s10551-010-0531-0.

Chen, M. A. (2007). Rethinking the informal economy: Linkages with the formal economy and the formal regulatory environment (DESA Working Paper No. 46). Retrieved from January 10, 2018, New York: http://www.un.org/esa/desa/papers/2007/ wp46_2007.pdf.

Coates, K., Holroyd, C., \& Leader, J. (2014). Managing the forgotten north: Governance structures and administrative operations of Canada's provincial norths. The Northern Review, 38, 6-54. 
Corbin, J. M., \& Strauss, A. (1990). Grounded theory research: Procedures, canons, and evaluative criteria. Qualitative Sociology, 13(1), 3-21. https://doi.org/10.1007/bf00988593.

Darbi, W. P. K., Hall, C. M., \& Knott, P. (2016). The informal sector: A review and agenda for management research. International Journal of Management Reviews, 00(00), 1-24. https://doi. org/10.1111/ijmr.12131.

De Castro, J. O., Khavul, S., \& Bruton, G. D. (2014). Shades of grey: How do informal firms navigate between macro and meso institutional environments? Strategic Entrepreneurship Journal, 8(1), 75-94. https://doi.org/10.1002/sej.1172.

Eweje, G. (2006). Environmental costs and responsibilities resulting from oil exploitation in developing countries: The case of the Niger Delta of Nigeria. Journal of Business Ethics, 69(1), 27-56. https://doi.org/10.1007/s10551-006-9067-8.

Feige, E. L. (2016). Reflections on the meaning and measurement of unobserved economies: What do we really know about the "shadow economy"? Journal of Tax Administration, 2(1), 5-41.

Flicker, S., Travers, R., Guta, A., McDonald, S., \& Meagher, A. (2007). Ethical dilemmas in community-based participatory research: Recommendations for institutional review boards. Journal of Urban Health: Bulletin of the New York Academy of Medicine, 84(4), 478-493. https://doi.org/10.1007/s1152 4-007-9165-7.

Fortin, B., Lacroix, G., \& Pinard, D. (2010). Evaluation of the underground economy in Quebec: A microeconomic approach. International Economic Journal, 24(4), 463-479. https://doi. org/10.1080/10168737.2010.525983.

Ghersi, E. (1997). The growing importance of informality and possibilities for integration. In O. Lippert \& M. Walker (Eds.), The underground economy: Global evidence of its size and impact (pp. 223-237). Vancouver: The Fraser Institute.

Godfrey, P. C. (2011). Toward a theory of the informal economy. Academy of Management Annals, 5(1), 231-277. https://doi. org/10.1080/19416520.2011.585818.

Government of Canada. (2014). Tri-council policy statement: Ethical conduct for research involving humans. (TCPS2 2014). Ottawa, Ontario: Secretariat on Responsible Conduct of Research. Retrieved from March 25, 2017, http://www.pre.ethics.gc.ca/ eng/policy-politique/initiatives/tcps2-eptc2/chapter9-chapitre9/.

Hart, K. (1973). Informal income opportunities and urban employment in Ghana. The Journal of Modern African Studies, 11(1), 61-89.

International Labour Organization. (2013). Measuring informality: A statistical manual on the informal sector and informal employment. Retrieved from May 28, 2017, Geneva: http://www.ilo.org/ wcmsp5/groups/public/---dgreports/---dcomm/---publ/documents/ publication/wcms_222979.pdf.

Irarrazaval, I. (1997). Learning from the informal sector. In O. Lippert \& M. Walker (Eds.), The underground economy: Global evidence of its size and impact (pp. 239-254). Vancouver: The Fraser Institute.

Joassart, P. (2010). Measuring informal work in developed nations. In E. Marcelli, C. C. Williams \& P. Joassart (Eds.), Informal work in developed nationsRoutledge advances in heterodox economics (pp. 34-44). London: Routledge.

Johnson, J., \& Holub, M. J. (2003). Questioning organizational legitimacy: The case of U.S. expatriates. Journal of Business Ethics, 47(3), 269-293.

Khlif, H., Guidara, A., \& Hussainey, K. (2016). Sustainability level, corruption and tax evasion: A cross-country analysis. Journal of Financial Crime, 23(2), 328-348.

Marcelli, E., Williams, C. C., \& Joassart, P. (2010). Introduction. In E. Marcelli, C. C. Williams \& P. Joassart (Eds.), Informal work in developed nationsRoutledge advances in heterodox economics (pp. 1-7). London: Routledge.
McGahan, A. M. (2012). Challenges of the informal economy for the field of management. Academy of Management Perspectives, 26(3), 12-21.

Mirus, R., Smith, R. S., \& Karoleff, V. (1994). Canada's underground economy revisited: Update and critique. Canadian Public Policy, 20(3), 235-252. https://doi.org/10.2307/3551952.

Natcher, D. C. (2009). Subsistence and the social economy of Canada's Aboriginal north. Northern Review, 30, 83-98.

Northern Development Ministers Forum. (2016). Saskatchewan. Retrieved from December 12, 2016, http://www.focusnorth.ca/ english/province/saskatchewan.php.

Ommer, R. E., \& Turner, N. J. (2004). Informal rural economies in history. Labour, Spring, 53, 127-157.

Petersen, H.-G., Thießen, U., \& Wohlleben, P. (2010). Shadow economy, tax evasion, and transfer fraud-Definition, measurement, and data problems. International Economic Journal, 24(4), 421441. https://doi.org/10.1080/10168737.2010.525973.

Schmidt, H. (2009). Conducting research with First Nations and for First Nations: A reflective study of Aboriginal empowerment within the context of participatory research. (Doctor of Philosophy), York University, Toronto.

Schneider, F., Buehn, A., \& Montenegro, C. E. (2010). New estimates for the shadow economies all over the world. International Economic Journal, 24(4), 443-461. https://doi.org/10.1080/10168 737.2010 .525974$.

Schneider, F., Raczkowski, K., \& Mróz, B. (2015). Shadow economy and tax evasion in the EU. Journal of Money Laundering Control, 18(1), 34-51.

Sisco, A., \& Stonebridge, C. (2010). Toward thriving Northern communities. Retrieved from Ottawa.

Statistics Canada. (2011). NHS Aboriginal Population Profile, Division No. 18, CDR, Saskatchewan 2011. Retrieved from August 5, 2016, http://www12.statcan.gc.ca/nhs-enm/2011/dp-pd/aprof /search-recherche/lst/page.cfm?Lang $=\mathrm{E} \& \mathrm{TABID}=1 \& \mathrm{GEOCO}$ $\mathrm{DE}=47$.

Strauss, A., \& Corbin, J. (1990). Basics of qualitative research: Grounded theory procedures and techniques. London: Sage.

Suchman, M. C. (1995). Managing legitimacy: Strategic and institutional approaches. The Academy of Management Review, 20(3), 571.

Swanson, L. A., Leader, J., \& Landrie-Parker, D. (2016). Effectively engaging with Indigenous communities through multi-methods qualitative data collection and an engaged communications plan. Engaged Scholar Journal, 2(1), 39-56. https://doi.org/10.15402 lesj.v2i2.174.

Thomas, J. J. (1992). Informal economic activity. Ann Arbor: University of Michigan Press.

Waiser, W. A. (2016). A world we have lost: Saskatchewan before 1905. Markham, ON: Fifth House.

Wang, C. C., \& Burris, M. A. (1997). Photovoice: Concept, methodology, and use for participatory needs assessment. Health Education \& Behavior, 24(3), 369-387.

Webb, J. W., Ireland, R. D., \& Ketchen, D. J. (2014). Toward a greater understanding of entrepreneurship and strategy in the informal economy. Strategic Entrepreneurship Journal, 8(1), 1-15. https ://doi.org/10.1002/sej.1176.

Webb, J. W., Tihanyi, L., Ireland, R. D., \& Sirmon, D. G. (2009). You say illegal, I say legitimate: Entrepreneurship in the informal economy. Academy of Management Review, 34(3), 492-510. https ://doi.org/10.5465/amr.2009.40632826.

Welter, F., Smallbone, D., \& Pobol, A. (2015). Entrepreneurial activity in the informal economy: A missing piece of the entrepreneurship jigsaw puzzle. Entrepreneurship \& Regional Development, 27(5/6), 292-306. https://doi.org/10.1080/08985626.2015.10412 59. 